\title{
Integrated Water Vapor Field and Multiscale Variations over China from GPS Measurements
}

\author{
SHUANGGEN J IN \\ Korea Astronomy and Space Science Institute, Daejeon, South Korea \\ Z. LI \\ National Geomatics Center of China, Beijing, China \\ J. $\mathrm{CHO}$ \\ Korea Astronomy and Space Science Institute, Daejeon, South Korea
}

(M anuscript received 27 November 2007, in final form $27 \mathrm{M}$ arch 2008)

\begin{abstract}
A BSTRACT
Water vapor plays a key role in the global hydrologic cycle and in climatic change. However, the distribution and variability of water vapor in the troposphere are not understood well-in particular, in China with the complex Tibetan Plateau and the influence of the A sian and Pacific monsoons. In this paper, continuous global positioning system (GPS) observations for 2004-07 in China are used to produce precipitable water vapor (PWV) measurements; these measurements constitute the first investigation of PWV distribution and variability over China. It has been found that the stronger water vapor values are in southeastern China and the lower water vapor values are in northwestern China. These distributions are mainly affected by the latitude, topographical features, the season, and the monsoon. Water vapor variations over China are mainly dominated by seasonal variations. The strong seasonal cycles are in summer with maximum water vapor and in winter with minimum water vapor. The PWV in southeastern China has an annual amplitude of about $15 \mathrm{~mm}$, much larger than in northwestern China at about $4 \mathrm{~mm}$, and meanwhile the time of peak water vapor content is one month earlier than in other regions, probably because of the known rainy season (mei-yu). In addition, significant diurnal variations of water vapor are found over all GPS stations, with a mean amplitude of about $0.7 \mathrm{~mm}$, and the peak value occurs around noon or midnight, depending on geographic location and topographical features. The semidiurnal cycle is weaker, with a mean amplitude of about $0.3 \mathrm{~mm}$, and the first peak PWV value appears around noon.
\end{abstract}

\section{Introduction}

A tmospheric water vapor is a variable that interacts with the solar radiation and controls the thermodynamics and energy balance of the atmosphere. Therefore, water vapor plays a key role in the global hydrologic cycle and heat processes of the climate system. Integrated or precipitable water vapor (PWV) is an impor-

Corresponding author address: D r. Shuanggen J in, Korea A stronomy and Space Science Institute, 61-1, Whaam-dong, Y useong-gu, D aejeon 305-348, South Korea.

E-mail: sgjin@kasi.re.kr tant indicator of water vapor variability in the lower troposphere and related climate processes. It represents the water vapor storage in the column of the atmosphere in terms of water budget, as a result of the balance among precipitation, evaporation, and convergence of humidity (Fontaine et al. 2003). PWV concentrations possess a high degree of spatial and temporal variability that depends on the season, topographic features, and other local and regional climatic conditions, especially in China with the highest Tibetan Plateau and being subject to the $A$ sian and Pacific monsoons. H owever, the spatial and temporal distribution features of water vapor concentrations were not understood well until radiosonde data became available (Bannon 


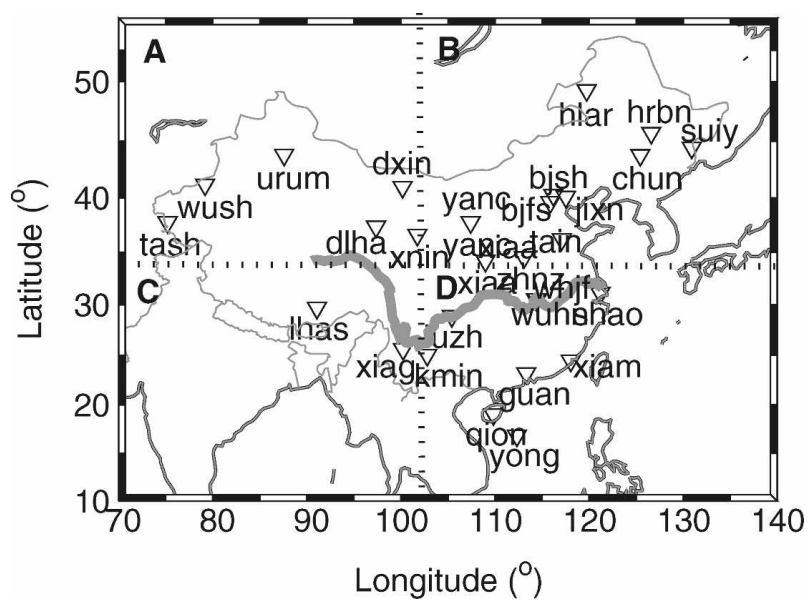

FIG. 1. Distribution of the CM ONC GPS sites in China: northwestern $C$ hina is labeled as $A$, northeastern $C$ hina is labeled as $B$, southwestern China is labeled as $C$, and southeastern China is labeled as $D$. The thick line in the middle is the $Y$ angtze $R$ iver valley.

and Steele 1960; Starr et al. 1965). A Ithough many studies were done with radiosonde data in different regions (e.g., A ngell et al. 1984; Hense et al. 1988; $G$ affen et al. 1992; Elliott et al. 1995), high-time-resolution observations are limited (e.g., hourly or diurnal variations). Global positioning systems (GPS) have recently been widely developed as all-weather, high-spatial-andtemporal-resolution, low-cost remote sensing systems of the atmosphere (Bevis et al. 1994; HernándezPajares et al. 2001), as compared with conventional techniques such as satellite radiometer sounding, ground-based microwave radiometer, and radiosondes (W estwater 1993). With independent data from other instruments-in particular, water vapor radiometersit has been demonstrated that water vapor can be retrieved using ground-based GPS observations with the same level of accuracy as radiosondes and microwave radiometers (Elgered et al. 1997; R ocken et al. 1993; D uan et al. 1996; E mardson et al. 1998; Tregoning et al. 1998). Furthermore, G PS-derived water vapor has high resolutions (0.5-2 h). Therefore, GPS can be used to study short-time-scale variations of water vapor as well as its distribution.

The national project "Crustal Movement Observation N etwork of China" (CM O NC) contained a nationwide fiducial network with about 28 continuous GPS observation sites (see Fig. 1). These continuous GPS observations can be used to compute daily station position, PWV , and total electron content, which are used for crustal deformation monitoring, meteorological, and space environments over China. In this paper, the 2-h water vapor field over China is retrieved from continuous G PS observations of the CM O NC for 2004-07 and the first use of these data to study PWV distributions and multiscale variations is presented.

\section{GPS water vapor retrievals}

The available continuous GPS observation data for 2004-07 are processed by B ernese software ( $D$ ach et al. 2007) with International GPS Services (IGS) final orbits, International Earth R otation and R eference Systems Service (IE R S) E arth orientation parameters, azimuth- and elevation-dependent antenna phase center models, and newly recommended strategies (B yun et al. 2005; J in et al. 2007). The unknown parameters contain station coordinates, atmospheric gradient, zenith tropospheric delay (ZTD) every 2 h, GPS satellite orbital parameters, and so on.

The ZTD is the integrated refractivity along a vertical path through the neutral atmosphere:

$$
\mathrm{ZTD}=c \tau=10^{-6} \int_{0}^{\infty} N(s) d s,
$$

where $c$ is the speed of light in a vacuum, $\tau$ is the delay measured in units of time, and $N$ is the neutral atmospheric refractivity. The refractivity $N$ is empirically related to standard meteorological variables as ( $D$ avis et al. 1985)

$$
N=k_{1} \rho+k_{2} \frac{P_{w}}{Z_{w} T}+k_{3} \frac{P_{w}}{Z_{w} T^{2}},
$$

Where $k_{i}(i=1,2,3)$ are constants given by B evis et al. (1994), $\rho$ is the total mass density of the atmosphere, $P_{w}$ is the partial pressure of water vapor, $Z_{w}$ is a compressibility factor close to unity that accounts for the small departures of moist air from an ideal gas, and $T$ is the temperature in kelvins. The integral of the first term of E q. (2) is the hydrostatic component $N_{h}$, and the integral of the remaining two terms is the wet component $N_{w}$. Thus, ZTD is the sum of the hydrostatic or "dry" delay (ZHD) and nonhydrostatic or "wet" delay (ZWD), due to the effects of dry gases and water vapor, respectively. The dry component ZHD is related to the atmospheric pressure at the surface, and the wet component ZWD can be transformed into PWV by the mapping function $\Pi=\left\{10^{-6} \rho R_{v}\left[\left(k_{3} / T_{m}\right)+k_{2}^{\prime}\right]\right\}^{-1}$, where $\rho$ is the density of liquid water, $R_{v}$ is the specific gas constant for water vapor, $T_{m}$ is a weighted mean temperature from $T_{m}=70.2+0.72 T_{s}$, where $T_{s}$ is the surface temperature in kelvins (B evis et al. 1994), $k_{2}^{\prime}=$ $k_{2}-m k_{1}$, and $m$ is $M_{w} / M_{d}$, the ratio of the molar masses of water vapor and dry air ( $D$ avis et al. 1985). Some GPS sites have a lack of collocated surface temperature and pressure data; the absent surface pressures are interpolated from global 3-h surface synoptic 

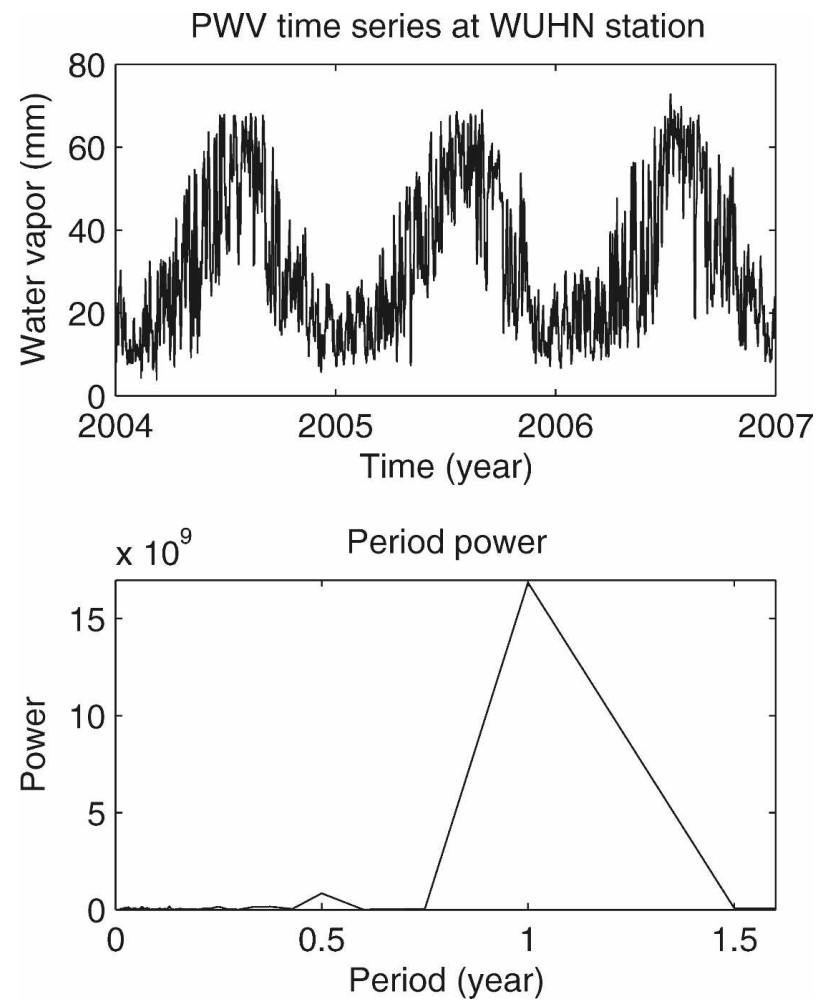

FIG. 2. (top) PWV time series at WUHN station for 2004-07 and (bottom) period power chart.

observations from the Comprehensive O cean-A tmosphere Dataset (COA DS; http://dss.ucar.edu/datasets/ ds464.0) and the absent surface temperatures are estimated from the 6-hourly $N$ ational Centers for $E$ nvironmental Prediction- $\mathrm{N}$ ational Center for A tmospheric Research reanalysis products (ftp://ftp.cdc.noaa.gov/ $D$ atasets/ncep.reanalysis; $W$ ang et al. 2005). Thus, 2-h PWV time series for 2004-07 over China can be obtained from GPS-derived ZTD and surface pressure and temperature data, and the uncertainty of PWV is about $0.5-1.5 \mathrm{~mm}$ because of errors in ZTD, surface pressure, and temperature. For example, Fig. 2 shows the water vapor time series at the Wuhan, China, (WUHN) station for 2004-07. In general, the GPSderived PWV agrees well with that from radiosonde in B eijing and Shanghai, China, and with collocated very long baseline interferometry (VLBI) observations in Shanghai, with a mean difference of about $1.8 \mathrm{~mm}$ and mean root-mean-square (rms) of about $1.5 \mathrm{~mm}$.

\section{Results and discussion}

\section{a. Water vapor distribution}

Precipitable water vapor is a key parameter of the atmosphere and varies with season, topographic features, and other climatic conditions. The 3-yr PWV

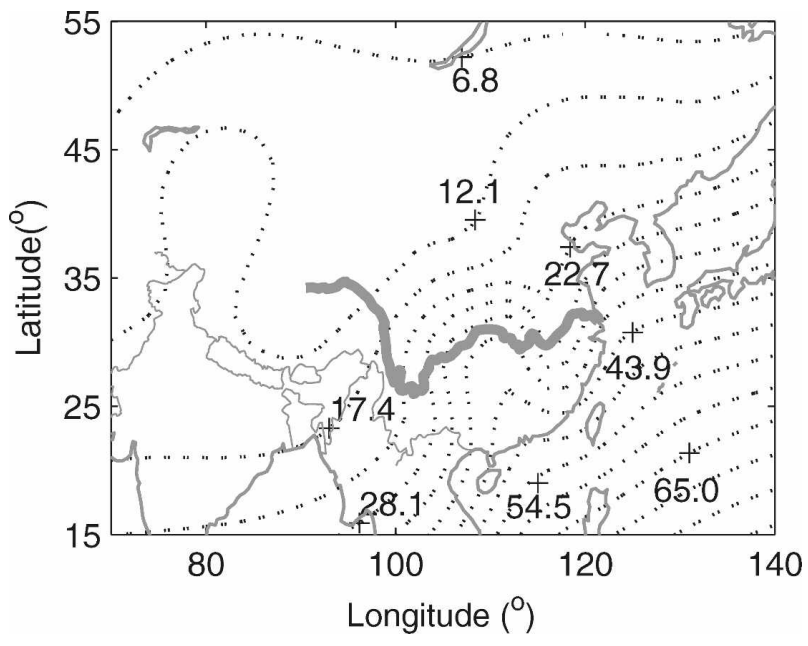

FIG. 3. Contour distribution of mean PWV (mm) over China. The mean PWV at each site was calculated from the 2-h PWV time series over $3 \mathrm{yr}$. The thick line in the middle is the $Y$ angtze R iver valley.

time series with 2 -h sampling at 28 GPS sites over China provide an important data source to investigate water vapor distribution features and to understand its variability and change. The mean PWV was calculated from the 2-h PWV time series over $3 \mathrm{yr}$ with the sample size of about 12000 at each station. Figure 3 shows the distribution of mean PWV as a contour with kriging interpolation (I saaks and Srivastava 1989). O ver northern and western China the water vapor content is lower, ranging from 6.8 to $20.0 \mathrm{~mm}$, and over the $Y$ angtze $R$ iver valley (shown by the thick line in the middle part of Fig. 3) and southeast China it is about $40.0-65.0 \mathrm{~mm}$. It can be seen that the water vapor distribution over China has a latitudinal feature, as typified in the east of

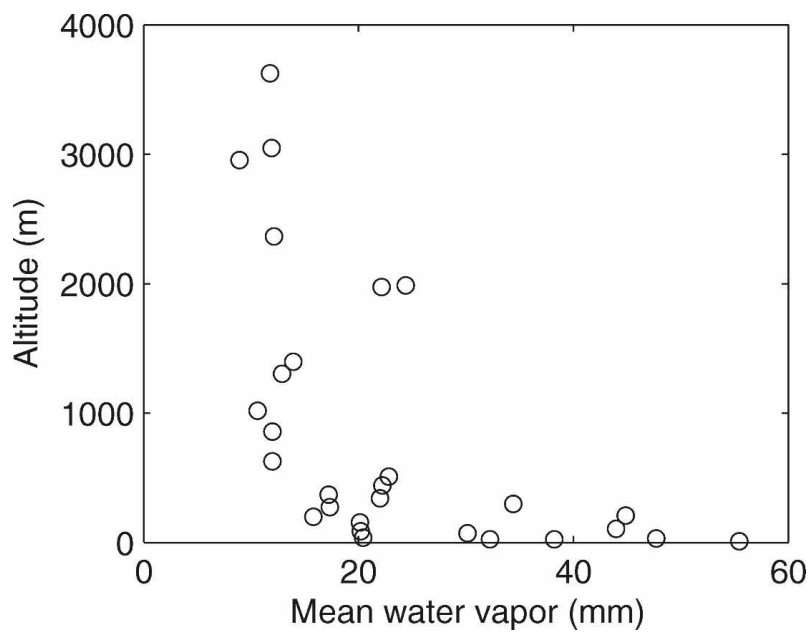

FIG. 4. Distribution of mean PWV with altitude (above global mean sea level). The circles represent the mean PWV at each site. 


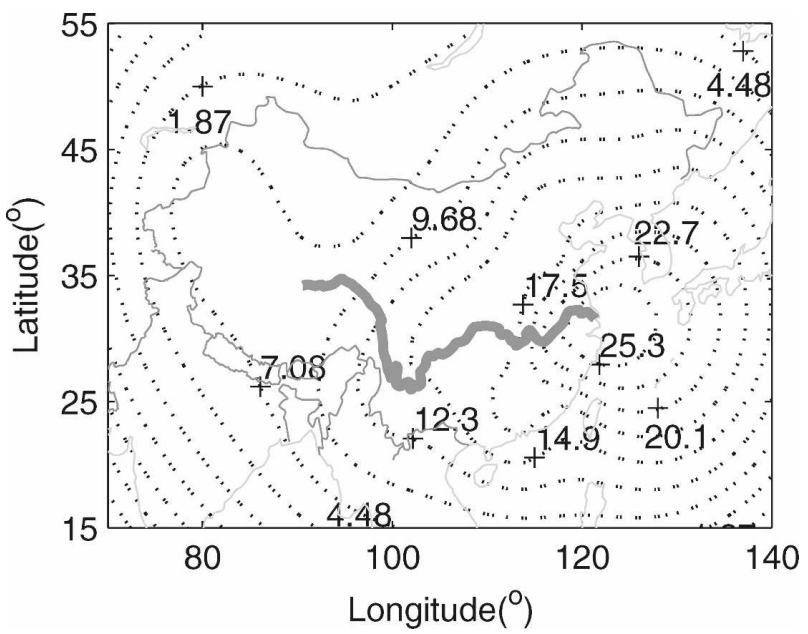

FIG. 5. Contour distributions of annual PWV amplitudes over China.

China. As the latitude increases, the water vapor amount decreases, with an obvious difference between southern China and northern China. The distribution feathers of PWV closely match China's geographical locations and probably reflect the influence of the A sian and Pacific monsoons (Chang 2004). Higher PWV in the southeast of Tibet is due to water vapor transportation from the Bay of $B$ engal and adjacent areas (Z ou et al. 1990). A t the same latitude, the water vapor over western China is lower than over eastern China, which may be caused by a colder atmosphere over the high, snow-covered surface over the western areas (e.g., Tibet). Figure 4 shows the distribution of mean PWV with altitude (above global mean sea level). The circle represents the mean PWV at each site, with

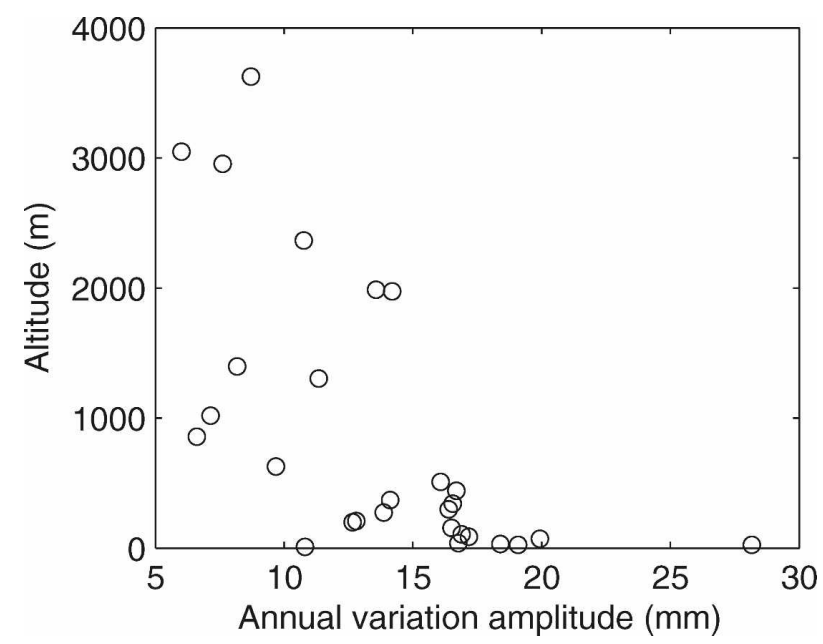

FIG. 6. Distribution of annual PWV variation amplitudes with altitude. The circles represent annual PWV variation amplitude at each site.

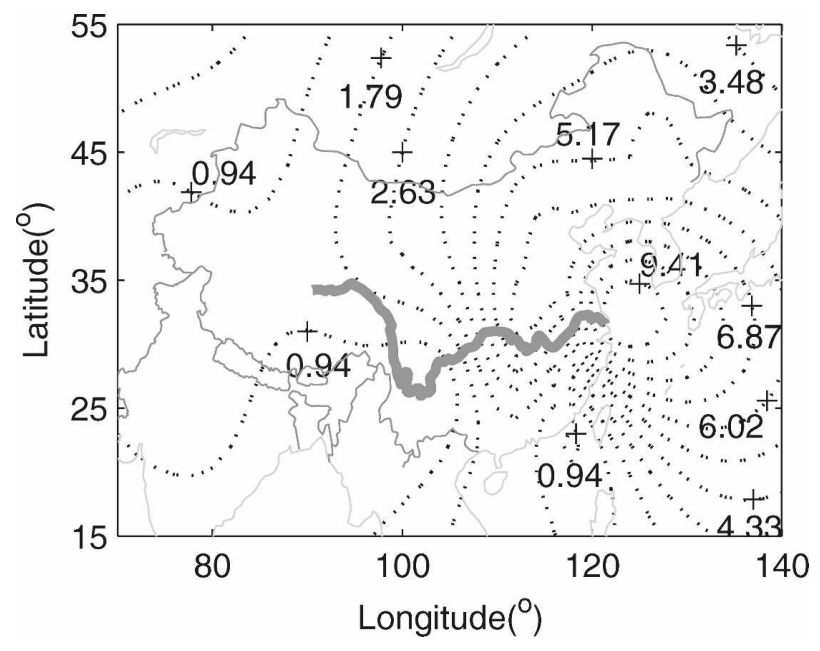

FIG. 7. Contour distributions of semiannual PWV amplitudes over China.

uncertainty of $0.5-1.5 \mathrm{~mm}$. A n obvious descent of the water vapor content is seen with increasing elevation. Therefore, the distribution of atmospheric water vapor over China is mainly dominated by the latitude, topographical features, and climatic conditions. In addition, because of nonuniform GPS station distribution-in particular, in western China-the interpolated water vapor distribution features need to be further investigated with future denser observations.

\section{b. Seasonal variations of water vapor}

We analyzed all of the PWV time series at each GPS station with fast Fourier transform and found that the most marked periods of PWV time series at all GPS

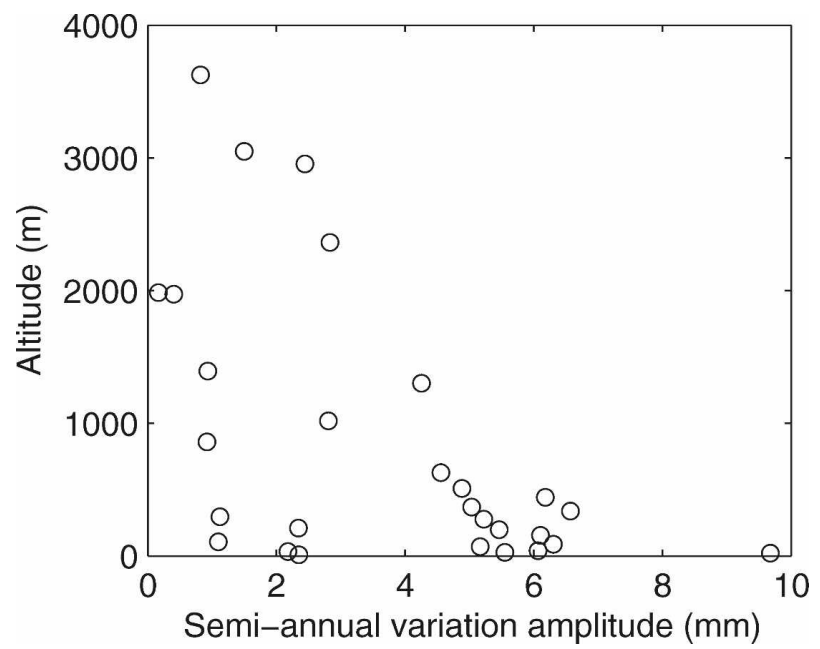

FIG. 8. Distribution of semiannual PWV variation amplitudes with altitude. The circles represent semiannual PWV variation amplitude at each site. 


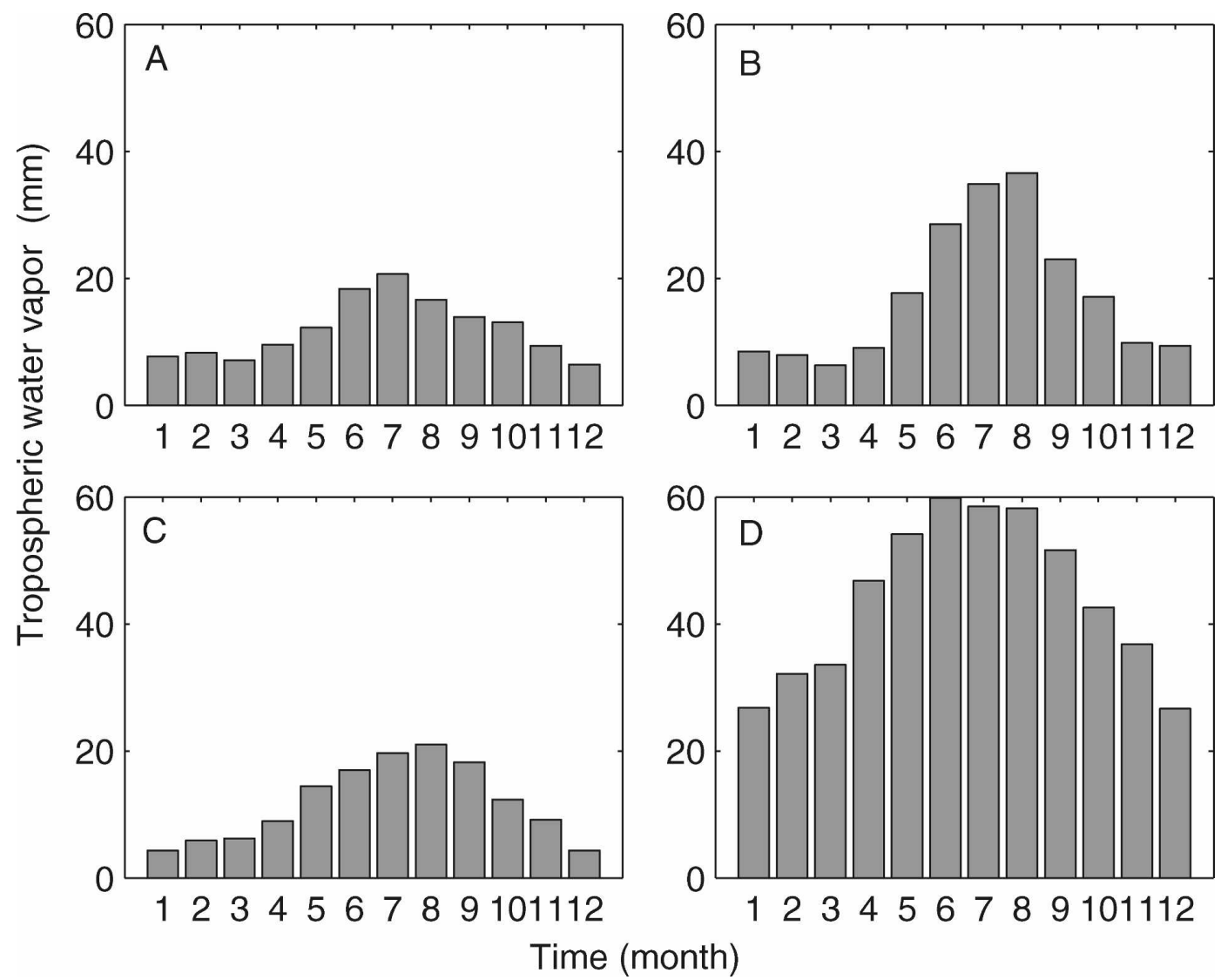

FIG. 9. Distribution of monthly PWV at the four subregions (A-D) marked in Fig. 1.

stations are about 1 and 0.5 yr. For example, Fig. 2 (bottom panel) shows the period power chart of PWV time series at the W U H N GPS site. The strong 1-yr and weak $0.5-y r$ periods have shown clear significant annual and weak semiannual variations, respectively. The characteristics of annual and semiannual terms at each site are exacted from 3-yr PWV time series. The uncertainty is about 0.7 and $0.4 \mathrm{~mm}$ for annual and semiannual amplitudes, respectively. The strong seasonal cycles are in summer with a maximum water vapor because of the influence of a moist summer monsoon and in winter with a minimum water vapor because of cold temperatures and dry weather. Figure 5 shows the amplitude of annual water vapor variations over China. The higher amplitudes are found in mid-eastern China with about $25.3 \mathrm{~mm}$, and the lower amplitudes are focused on western China. The annual-variation amplitudes are closely related to the topographic elevation (see Fig. 6). The semiannual-variation amplitudes are weak, with approximately several millimeters, much lower than annual variations-in particular, in western China with insignificant semiannual variations (Fig. 7) that are also related to the topographic elevation (see Fig. 8).
Based on the topographic features, China is divided into four subregions in Fig. 1 marked as A (northwestern China), B (northeastern China), C (southwestern China), and $D$ (southeastern China). The mean monthly medians of each subregion are obtained from 3-yr PWV time series and are shown in Fig. 9. It can be

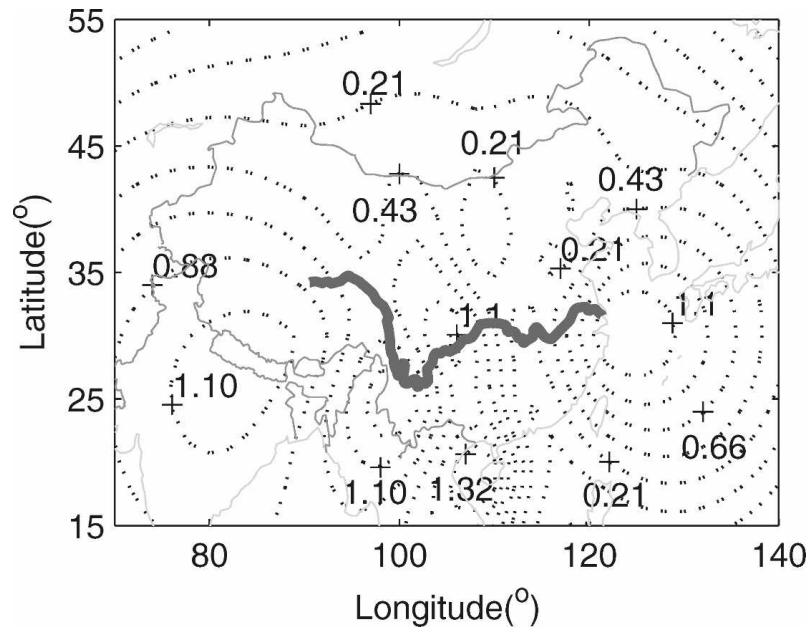

FIG. 10. Contour distributions of diurnal PWV amplitudes over China. 


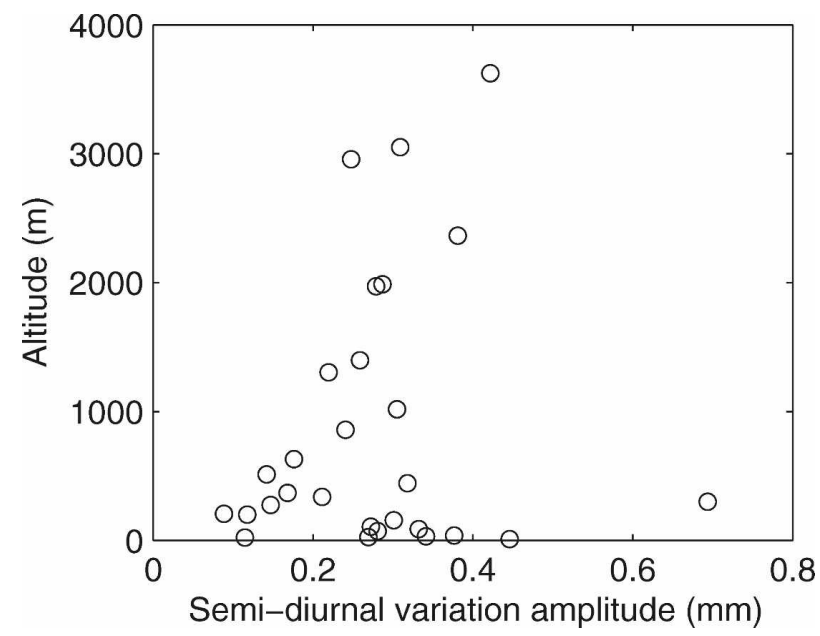

FIG. 11. D istribution of semidiurnal PWV variation amplitudes with altitude. The circles represent semidiurnal PWV variation amplitude at each site.

seen that the higher monthly water vapors are in eastern China ( $B$ and $D$ ) while western China ( $A$ and $C$ ) has lower monthly water vapors, but the entire water vapor in each region has a significant seasonal variation. The peak PWV content appears in J uly-A ugust, and the minimum PWV value occurs in January in southeastern China. However, the peak PWV values in the western $C$ hina regions ( $A$ and $C$ ) are much lower than the minimum value in southeastern China (D). The peak time also has an anomaly in different regions. For example, the time of peak water vapor content in southeastern China ( $D$ ) is one month earlier than other regions, probably due to the well-known rainy season (mei-yu) in southeastern China. In addition, water vapor in spring is a little lower than in autumn over China, which possibly causes a weak semiannual (i.e., 6-month period) variation of PWV. This difference is also consistent with Peixoto et al. (1981), who found during the study of large-scale atmospheric moisture processes that water vapor levels in spring and autumn are not identical but tend to resemble those in their antecedent seasons.

\section{c. Diurnal variation of water vapor}

Significant diurnal (24 h) variations of water vapor are found over all GPS stations, and the mean amplitude is about $0.7 \mathrm{~mm}$ with an uncertainty of about 0.1 $\mathrm{mm}$ (Fig. 10). The higher elevation has a larger amplitude of diurnal variation, with up to about $1.2 \mathrm{~mm}$. The
A

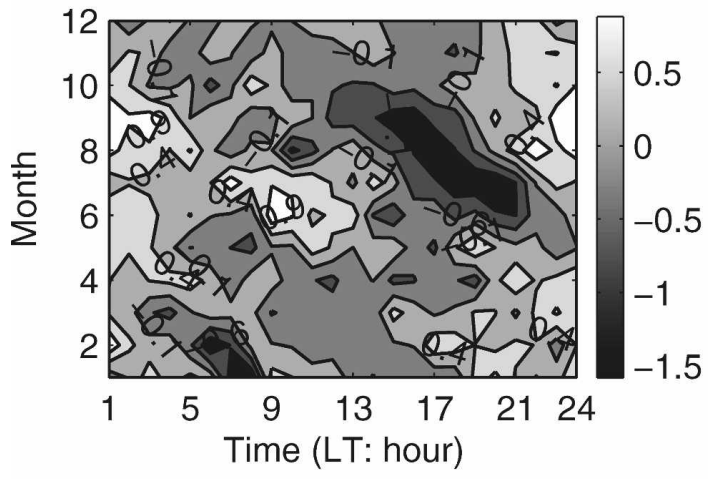

C

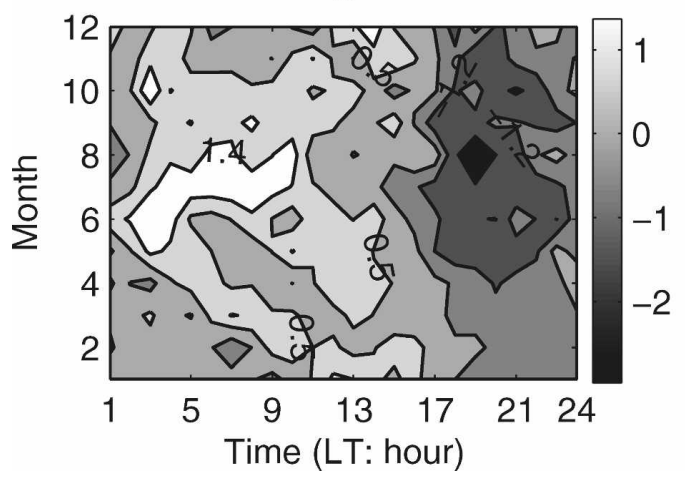

B
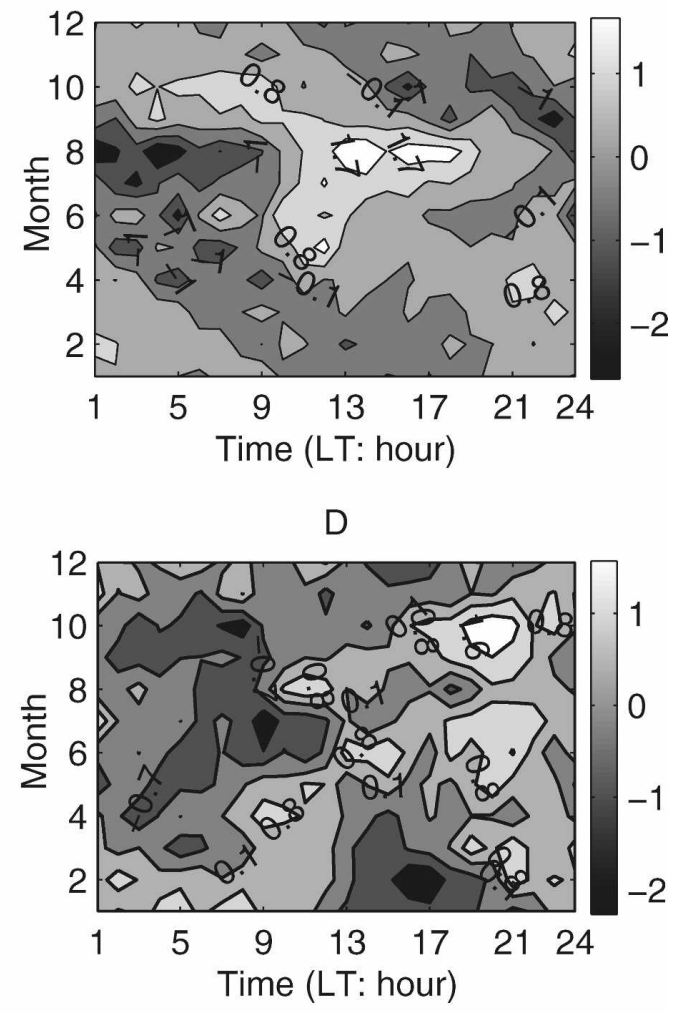

FIG. 12. M ean monthly variations of PWV diurnal cycle anomalies $(\mathrm{mm})$ at the four subregions (A -D) marked in Fig. 1. 

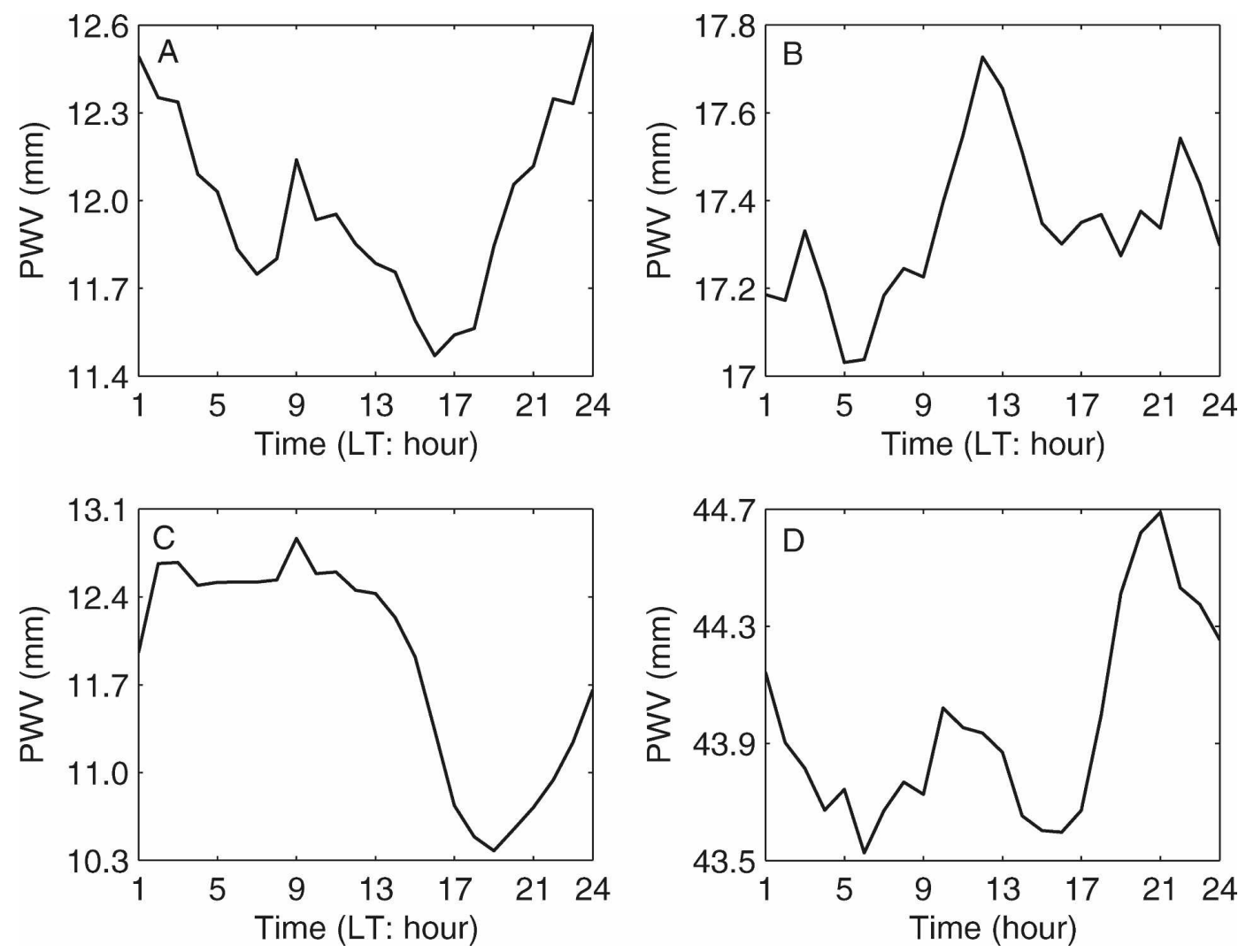

FIG. 13. M ean diurnal variation of PWV at the four subregions (A -D) marked in Fig. 1.

diurnal peak PWV values appear around noon between 0900 and $1300 \mathrm{LT}$ and around midnight between 2000 and $0000 \mathrm{LT}$, depending on locations, seasons, and so on. The semidiurnal ( $12 \mathrm{~h}$ ) cycle is weaker, with an amplitude of normally less than $0.5 \mathrm{~mm}$ (excluding one site, Lush, with about $0.7 \mathrm{~mm}$ ). The larger amplitudes are located at higher elevation areas (Fig. 11). The phase of the semidiurnal cycle is noisier than that of the diurnal variation, and the semidiurnal peak PWV values occur around noon and midnight (for the second cycle). Furthermore, the diurnal and semidiurnal cycles vary with the season. Figure 12 shows the monthly variation of diurnal PWV cycle anomalies at four subregions as marked in Fig. 1. R egion $C$ (i.e., Tibet area) has a marked diurnal variation, with the peak time in the morning between 0200 and $1400 \mathrm{LT}$. The mean diurnal variations of tropospheric water vapor at four subregions are clear to show the diurnal variation features (Fig. 13). The weak semidiurnal oscillations are significant at regions $A, B$, and $D$, excluding the winter season (D ecember-F ebruary), with a dominant diurnal oscillation. The peak times of semidiurnal oscillations are located in the day between 0900 and $1300 \mathrm{LT}$ and in the night between 2000 and $0000 \mathrm{LT}$, which may be linked to the diurnal cycle of convection.

\section{Conclusions}

The 3-yr tropospheric water vapor field is retrieved from continuous GPS observations of the CMONC for 2004-07, which are the first used to investigate the significant variability and distributions over broad and complex geomorphologic China. Distinct seasonal cycles and diurnal variations are found over all GPS stations. The stronger mean water vapors are in southeastern China while northwestern China has lower mean water vapors. The marked seasonal cycles are in summer with a maximum water vapor and in winter with a minimum water vapor. PWV in southeastern China has an annual amplitude of about $15 \mathrm{~mm}$, much larger than in northwestern China with about $4 \mathrm{~mm}$. $M$ eanwhile, the time of peak water vapor content is one month earlier than other regions, probably because of the well-known rainy season (mei-yu). The mean amplitude of significant diurnal variations of water vapor is about $0.7 \mathrm{~mm}$, and the peak diurnal PWV values occur around noon and midnight and are affected by the diurnal cycle of convective activities. The semidiurnal cycle is weaker, with an amplitude of normally less than $0.5 \mathrm{~mm}$ and the peak semidiurnal PWV values appear around noon and midnight (for the second 
cycle). The spatial distributions and variabilities of PWV are mainly dominated by the latitude, topographical features, the season, and the monsoon. In the future, these PWV datasets will be further applied in numerical prediction models, climatology, and so on.

Acknowledgments. The authors acknowledge the use of GPS data that were retrieved from the Crustal $M$ ovement O bservation N etwork of China (CM ONC). We also thank the referees for valuable suggestions that significantly improved the article. This work was supported by the Korea M eteorological A dministration $R$ esearch and Development Program under Grant CA TER 2006-3104.

\section{REFERENCES}

A ngell, J. K., W. P. Elliott, and M . E . Smith, 1984: Tropospheric humidity variations at Brownsville, Texas, and $\mathrm{G}$ reat Falls, M ontana, 1958-80. J. Climate Appl. Meteor., 23, 1286-1296.

Bannon, J. K., and L. P. Steel, 1960: A veraged water vapor contents of the air. Geophysical M emo. 102, U.K. M eteorological Office M.0.631b, $38 \mathrm{pp}$.

B evis, M., S. B usinger, S. Chiswell, T. A . Herring, R. A . A nthes, C. Rocken, and R. H. Ware, 1994: G PS meteorology: M apping zenith wet delays onto precipitable water. J. Appl. Meteor., 33, 379-386.

Byun, S. H., Y. B ar-Sever, and G. Gendt, 2005: The new tropospheric product of the International GNSS service. Proc. ION GNSS Conf., Long B each, CA , Institute of Navigation, 241-249.

Chang, C. P., 2004: East Asian Monsoon. World Scientific, 564 pp.

Dach, R., U. Hugentobler, P. Fridez, and M. M eindl, 2007: Bernese GPS software version 5.0. A stronomical Institute, U niversity of Bern, $612 \mathrm{pp}$.

D avis, J . L., T . A . H erring, I. Shapiro, A . R ogers, and G . Elgered, 1985: Geodesy by radio interferometry: Effects of atmospheric modeling errors on estimates of baseline length. $R a$ dio Sci., 20, 1593-1607.

D uan, J., and Coauthors, 1996: GPS meteorology: D irect estimation of the absolute value of precipitable water. J. Appl. Meteor., 35, 830-838.

E Igered, G ., J . J ohansson, B. R önnäng, and J . D avis, 1997: M easuring regional atmospheric water vapor using the Swedish Permanent GPS Network. Geophys. Res. Lett., 24, 26632666.

Elliott, W.P., R.J. Ross, and D.J. Gaffen, 1995: Water vapor trends over N orth A merica. Preprints, Sixth Symp. on Global Change Studies, D allas, TX, A mer. M eteor. Soc., 185-186.

Emardson, T. R., G. Elgered, and J. M . Johansson, 1998: Three months of continuous monitoring of atmospheric water vapor with a network of G PS receivers. J. Geophys. Res., 103, 18071820.

Fontaine, B ., P. R oucou, and S. Trzaska, 2003: A tmospheric water cycle and moisture fluxes in the West A frican monsoon: M ean annual cycles and relationship using NCE P/NCA R reanalysis. Geophys. Res. Lett., 30, 1117, doi:10.1029/ 2002G L 015834.

Gaffen, D. J., W. P. Elliott, and A. Robock, 1992: R elationship between tropospheric water vapor and surface temperatures as observed by radiosondes. Geophys. Res. Lett., 19, 18391879.

Hense, A ., P. K rahe, and H. Flohn, 1988: R ecent fluctuations of tropospheric temperature and water vapor in the tropics. $M e$ teor. Atmos. Phys., 38, 215-227.

Hernández-Pajares, M., J. M. J uan, J. Sanz, O . L. Colombo, and $H$. van der $M$ arel, 2001: A new strategy for real-time integrated water vapor determination in WADGPS networks. Geophys. Res. Lett., 28, 3267-3270.

I saaks, E. H., and R. M. Srivastava, 1989: An Introduction to Applied Geostatistics. Oxford U niversity Press, $561 \mathrm{pp}$.

J in, S. G., J. U. Park, J.H. Cho, and P. H. Park, 2007: Seasonal variability of GPS-derived zenith tropospheric delay (1994-2006) and climate implications. J. Geophys. Res., 112, D 09110, doi:10.1029/2006] D 007772.

Peixoto, J . P., D. A . Salstein, and R . D . R osen, 1981: Intra-annual variation in large-scale moisture fields. J. Geophys. Res., 86, $1255-1264$.

Rocken, C., R. H. Ware, T. V an Hove, F. Solheim, C. A Iber, J. Johnson, and M.G. Bevis, 1993: Sensing atmospheric water vapor with the global positioning system. Geophys. Res. Lett., 20, 2631-2634.

Starr, V. P., J. P. Peixoto, and A . R . Crisi, 1965: Hemispheric water balance for IGY. Tellus, 17, 463-471.

Tregoning, P., R. B oers, and D. O'B rien, 1998: A ccuracy of absolute precipitable water vapor estimates from G PS observations. J. Geophys. Res., 103, 701-710.

Wang, J., L. Z hang, and A. D ai, 2005: G lobal estimates of watervapor-weighted mean temperature of the atmosphere for G PS applications. J. Geophys. Res., 110, D 21101, doi:10.1029/ 2005] D 006215.

W estwater, E. R ., 1993: G round-based microwave remote sensing of meteorological variables. Atmospheric Remote Sensing by Microwave Radiometry, M. A . J anssen, E d., J ohn Wiley and Sons, 145-213.

Zou, J. S., J. Jiang, and M. H. H uang, 1990: Upper-Air Climatology. M eteorological Press, $239 \mathrm{pp}$. 